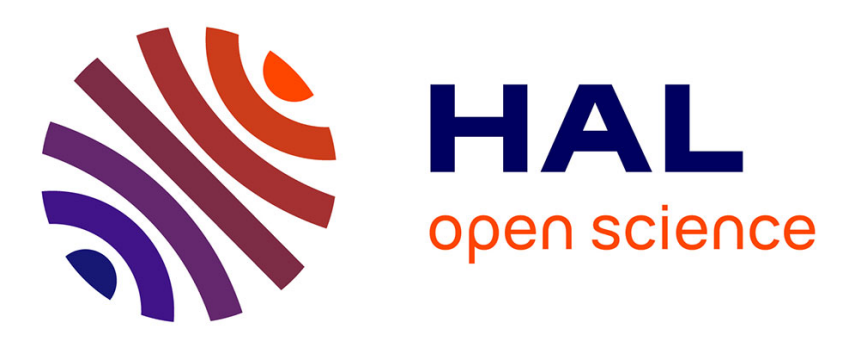

\title{
Simulation Study of Spacecraft Electrostatic Sheath Changes With the Heliocentric Distances from 0.044 to $1 \mathrm{AU}$
}

S. Guillemant, Vincent Génot, J.-C. Matéo-Vélez, Pierre Sarrailh, A. Hilgers, Philippe Louarn

\section{To cite this version:}

S. Guillemant, Vincent Génot, J.-C. Matéo-Vélez, Pierre Sarrailh, A. Hilgers, et al.. Simulation Study of Spacecraft Electrostatic Sheath Changes With the Heliocentric Distances from 0.044 to 1 AU. IEEE Transactions on Plasma Science, 2013, PP, pp.99. 10.1109/TPS.2013.2246193 • hal-00849836

\section{HAL Id: hal-00849836 https://hal.science/hal-00849836}

Submitted on 1 Aug 2013

HAL is a multi-disciplinary open access archive for the deposit and dissemination of scientific research documents, whether they are published or not. The documents may come from teaching and research institutions in France or abroad, or from public or private research centers.
L'archive ouverte pluridisciplinaire HAL, est destinée au dépôt et à la diffusion de documents scientifiques de niveau recherche, publiés ou non, émanant des établissements d'enseignement et de recherche français ou étrangers, des laboratoires publics ou privés. 


\title{
A Simulation Study of Spacecraft Electrostatic Sheath Changes with the Heliocentric Distances from 0.044 to $1 \mathrm{AU}$
}

\author{
S. Guillemant, V. Génot, J.-C. Matéo Vélez, P. Sarrailh, A. Hilgers, P. Louarn
}

\begin{abstract}
In this paper the electrostatic sheath of a simplified spacecraft is investigated for heliocentric distances varying from 0.044 to $1 \mathrm{AU}$, using the 3D Particle in Cell (PIC) software Satellite Plasma Interaction System (SPIS). The baseline context is the prediction of sheath effects on solar wind measurements for various missions including the Solar Probe Plus mission (perihelion at $0.044 \mathrm{AU}$ from the Sun) and Solar Orbiter (perihelion at $0.28 \mathrm{AU}$ ). The electrostatic sheath and the spacecraft potential could interfere with the low energy (a few tens of $\mathrm{eV}$ ) plasma measurements, by biasing the particle distribution functions measured by the detectors. If the spacecraft charges to large negative potentials, the problem will be more severe as low energy electrons will not be seen at all. The Solar Probe Plus and Solar Orbiter cases will be presented in details and extended to other distances through a parametric study, to investigate the influence of the heliocentric distance to spacecraft. Our main result is that for our spacecraft model the floating potential is a few volts positive from $1 \mathrm{AU}$ to about 0.3 AU while below $0.3 \mathrm{AU}$ the space charge of the photoelectrons and secondary electrons create a potential barrier that drives the spacecraft potential negative.
\end{abstract}

Index Terms - Potential barriers, Photoelectron sheath, Simulation Software, Spacecraft Charging

\section{INTRODUCTION}

$S_{\text {p }}^{\mathrm{E}}$ EVERAL coming scientific space missions consist of probes immersed in the Solar wind, at relatively close distances from the Sun. One first example is the Solar Probe Plus (SP+) NASA mission which aims at studying the close environment of the Sun (approaching as close as 9.5 solar radii above the Sun's surface). The launch is planned in 2018 and the first perihelion in 2021. At such distances, the expected environment of the probe should be quite hot and dense, leading the spacecraft and its onboard instruments to be

Manuscript received October 5, 2012; revised December 5, 2012. This work was supported by the European Space Agency Contract 4000102091/10/NL/AF, a Centre National des Etude Spatiales (CNES) grant, and a Région Midi-Pyrénées grant. This work was performed in the context of a Ph.D. cursus in cosupervision between the Research Institute in Astrophysics and Planetology (IRAP) and the National Office of Aerospatial Studies and Research (ONERA).

S. Guillemant, V. Génot and P. Louarn are with IRAP, 31028 Toulouse, France (e-mail: stanislas.guillemant@irap.omp.eu; vincent.genot@irap.omp.eu; philippe.louarn@irap.omp.eu).

J.-C. Matéo-Vélez and P. Sarrailh are with ONERA/DESP, 31055 Toulouse, France (e-mail: jean-charles.mateo_velez@onera.fr; pierre.sarrailh@onera.fr).

A. Hilgers is with the European Space Research and Technology Centre, European Space Agency, 2200 AG Noordwijk, The Netherlands (e-mail: alain.hilgers@esa.int).

Digital Object Identifier affected by surface charging. In particular, estimations of the satellite potential behavior in such plasmas are important to predict the possible biases on plasma and electric measurements. Furthermore two phenomena will increase the disturbances on the near probe environment: behind the probe the satellite velocity combined with the speed of the solar wind will create an ion wake, and high densities of photoelectrons and secondary electrons will generate a potential barrier for those particles and force their recollection by the front surfaces. Another mission is the European Space Agency (ESA) spacecraft: Solar Orbiter (SO). Less extreme conditions are there expected since the spacecraft will remain farther from the Sun, with a closest perihelion at 0.28 astronomical unit (AU). However the impact of such conditions need also to be studied to avoid biases on plasma measurements as the Solar Orbiter mission at perihelion will be immersed in a region where the average Solar photon flux is thirteen to sixteen times more intense than at $1 \mathrm{AU}$. The Bepi-Colombo mission will also cruise in this region.

Potential barriers in electrostatic sheath have already been discussed in many analytical or numerical studies in the past 40 years, in particular to explain observations on different satellites. One of the first is Guernsey and Fu (1970) [1] which introduces a calculation of the potential distribution in the neighborhood of a photo-emitting plate immersed in a plasma. Considering thermal electrons, photoelectrons and flowing ions, it is shown that two steady state potential distributions can exist. The first with a monotonically decreasing potential from its plate value to zero, and the second with a decreasing potential from its plate value until a (negative) minimum and then an increase to zero. This minimum negative potential, due to a high local density of photoelectrons, can prevent those particles from escaping the surrounding region of the emitting plate and force their recollection.

Potential barriers were primarily inferred around Earth orbiting satellites (they were indeed not directly measured). Following observations of recollected photoelectrons and secondary electrons on the ATS 6 spacecraft, Whipple (1976) [2] developed a theory for a spherically symmetric photoelectron sheath, including effects of ions, thermal electrons and secondaries. The aim was to determine whether the potential barrier responsible for the secondaries reflection was originating from those same particles or not. A comparison with the spacecraft data showed that the observed barrier of potentials were too large to be explained by the model (i.e. a spherically symmetric photoelectron or secondary electron sheath surrounding a uniformly charged spacecraft), and the authors concluded that the most probable 
explanation was that some portions of the ATS 6 surfaces were charged to different potentials

In the context of instruments for active control of spacecraft potential, Zhao et al. (1996) [3] proposed an analytical approach to compute the electrostatic barrier and compared to Geotail measurements. However this analysis is only relevant in the thick sheath approximation and does not consider the secondary electronic emission.

Thiébault et al. (2004) [4] studied the potential barrier in the electrostatic sheath around a conductive magnetospheric spacecraft, for cases of conductive spacecraft like Geotail and Cluster. A fully self-consistent analytical model of the plasma around an electron emitting central body was used to analyze the electrostatic sheath around an idealized spacecraft. It was shown by comparison with 3D Particle in Cell (PIC) simulations that non monotonic potential with negative potential barrier can exist all around a positively charged spacecraft (with Debye length of the order of the central body radius or more). This barrier may still surround the entire spacecraft even in the case of asymmetric illumination pattern with induced photoemission on only one side of the central body.

Referring to a near Sun environment mission - the Helios spacecraft - Isensee (1977) [5] presents 2D simulations of the plasma environment of the probe in the solar wind, at $0.2 \mathrm{AU}$ from the Sun. With a simplified conducting spacecraft, the consideration of $1 \mathrm{eV}$ mean energy photoelectrons and the expected Solar wind conditions, the author obtained a slightly positively charged satellite $(+2.9 \mathrm{~V})$, surrounded by negative plasma potentials in the wake and in the ram. In front of the sunlit face, due to high densities of photoelectrons, the local potential reached $-1.4 \mathrm{~V}$ and in the ion wake behind the probe: $-4.5 \mathrm{~V}$. The $1 \mathrm{eV}$ emitted photoelectrons are thus recollected by the surfaces of the probe.

Ergun et al. (2010) [6], through a three-dimensional selfconsistent code, solved the static potential structure surrounding a spacecraft in a high photoelectron environment (the Solar Probe Plus context at 0.044 AU to the Sun), and showed that a negatively charged satellite is obtained through high densities of secondary electron and photoelectron both emitted as Maxwellian functions with low temperatures (resp. 2 and $3 \mathrm{eV}$ ). The photoelectron densities in that study reached $10^{6} \mathrm{~cm}^{-3}$ (compared to ambient ions and electrons densities of about $\left.7 \times 10^{3} \mathrm{~cm}^{-3}\right)$ and decreased the potential surrounding the spacecraft enough to create a barrier for low energy electrons. Once this barrier is set up, it will bring the next emitted secondary and photoelectrons back to the spacecraft materials, leading them to decrease the spacecraft potential $\left(\Phi_{S C}\right)$, even after the structure is charged negatively. The secondary particles recollection is problematic for the plasma instruments, especially the secondary electron recollection which can occur all around the spacecraft.

Those phenomena have been studied in detail in Guillemant et al. (2012) [7] using the Spacecraft Plasma Interaction System (SPIS) software, through simulations with more realistic physical and numerical processing, in particular using full PIC instead of hybrid populations modelling. To widen the perspectives a parametric study considered more realistic parameters for this near Sun environment. The potential barriers were always present, with an intensity depending on the varying input conditions.

Those publications encourage advanced studies on the formation and profile of the potential barriers depending on the heliocentric distance, and the effects on the satellite floating potential. In this paper the limits of this so called "near Sun environment" will be studied: the evolution of the potential barriers farther from the Sun, the critical distance for their existence, and the situation at the orbit of Solar Orbiter (at $0.25 \mathrm{AU}$ ). This is achieved through a parametric study where only the distance to the Sun varies (and consequently the local plasma parameters and Sun flux for 10 distances between $0.044 \mathrm{AU}$ to $1 \mathrm{AU}$ ), but keeping the same geometry model.

In the following section II presents the physics involved in the simulated environments, the SPIS tool for the parametric study and the simulations set up. Section III presents the simulation results for 1) the Solar Probe Plus case at $0.044 \mathrm{AU}$ (closest approach distance), 2) the Solar Orbiter case at 0.25 AU (closest approach distance) and 3) an overview of all the results for the 10 different positions.

\section{MODELLING}

\section{A. Environments, spacecraft dimensions and covering material}

The heliocentric distances selected for this parametric study are presented in Table 1. It gathers the essential physical environment parameters that have to be considered for such simulations. Plasma characteristics are derived from Helios data (Krasnoselskikh V. and Maksimovic M. private communications). The solar wind velocity is discretized for the different positions between Earth and 0.044 AU from the model of Parker (Parker E. N. 1958 [8]). The spacecraft geometry used for all simulations is a cylinder ( $1 \mathrm{~m}$ radius and $2 \mathrm{~m}$ long), covered with Indium Tin Oxide (ITO) conducting material.

In this study below $1 \mathrm{AU}$, the emitted photoelectron current is always the largest compared with others (see the estimated photo-emitted current density $J_{p h}$ given on Table 1 ). At first order, neglecting the ions and secondary electrons, the currents on spacecraft will be balanced when the net photoelectron current $I_{p h}$ equalizes the collected thermal electron current $I_{\text {the }}$. Consequently at the equilibrium state a large proportion of photoelectrons is recollected. Assuming a Maxwell Boltzmann regime:

$$
I_{\text {the }}=I_{p h}(\text { emitted }) \exp \left(\frac{-e \Phi_{S C}}{k_{B} T_{p h}}\right) .
$$

with $k_{B}$ the Boltzmann constant, $T_{p h}$ the photoelectron temperature and $e$ the photoelectron charge, therefore the spacecraft potential is a priori expected to be of a few times $\left(k_{B} T_{p h} / e\right)$ in order to recollect the fraction of photoelectrons necessary to equalize the other current.

However Ergun et al. (2010) [6] and Guillemant et al. (2012) [7] showed in a similar geometry (a cylinder) that negative charging is possible at $0.044 \mathrm{AU}$ from the Sun, due to potential barriers induced by large densities of photoelectrons 
(see Section I). Indeed in the ram region, below $1 \mathrm{AU}$, the UV flux generates densities of photoelectrons that locally surpass thermal electrons. The plasma potential in the region close to the sunlit surface is ruled by photoelectrons and their Debye length $\lambda_{p h}$ (smaller than the one of thermal electrons $\lambda_{\text {the }}$ ). Different possibilities arise, depending on the distance between the satellite and the Sun. 1) In a very close case like $0.044 \mathrm{AU}, \lambda_{\text {ph }}$ is much smaller than the spacecraft size which makes the local potential barrier very close to the surface and the space charge may be considered as 1 dimensional. In this case the "thin sheath" approximation is valid and the ChildLangmuir's law for space-charge limited flow is applicable. The photoelectron recollection is in this case very efficient through the space charge and the spacecraft is not necessarily positively charged; 2 ) in a farther case, when $\lambda_{\text {ph }}$ is comparable to the size of the spacecraft: the sheath becomes 3 dimensional, the barrier is farther from the emitting surface, decreasing the recollection rate of photoelectrons. This is the "thick sheath" approximation for which the spacecraft floating potential increases consequently. There is no significant effect of the space-charge and it is the positive spacecraft floating potential that makes the photoelectrons to be recollected. In this paper we examine where the transition between these two regimes occurs for the given spacecraft geometry and material.

The ion wake geometry is also important for the overall potential distribution. Depending on the Mach number, the ion temperature and the spacecraft geometry and potential, the ion wake will follow different morphologies. Typical wake geometries are sketched in Engwall et al. (2006) [18], concerning a spherically shaped and positively charged spacecraft. If the ion flow energy is much higher than the probe potential the wake will be cylindrically shaped (narrow wake case), if not: ions will scatter off the positive electrostatic potential from the spacecraft (creating an enhanced wake). In the simulations presented hereafter, we extend Engwall et al. (2006) [18] with a negatively charged satellite regime. The environment closest to the Sun will generate another ion wake morphology: a "bubble wake" (in hot and dense plasma regions, when the ion depletion is quite efficiently repopulated by ions). The "cylinder wake" will be encountered farther from the Sun (in colder plasmas, with an enhanced or narrowed extremity depending on the sign of $\left.\Phi_{S C}\right)$. The wake geometry will constrain the minimum potential at its center, leading to different depths of potential barriers and recollection rates for secondary electrons. This wake represents a potential barrier for secondary electrons that are emitted from all exposed faces of the satellite even from the rear side, different from photoelectrons.

\section{B. SPIS tool for simulations}

The simulation tool used in this study is SPIS, a software development project of the European Space Agency (ESA). It is developed as an open source and versatile code with the support of the Spacecraft Plasma Interaction Network in Europe (SPINE) community. The first development phase of the project has been performed by ONERA/DESP, Artenum and University Paris VII (through the ESA contract Nbr: $16806 / 02 / \mathrm{NL} / \mathrm{JA}$ ). Some developments were funded by the French space agency (CNES). It is a simulation software based on an electrostatic 3D unstructured Particle-In-Cell plasma model and consisting of a JAVA based highly modular Object Oriented library, called SPIS/NUM. More accurate, adaptable and extensible than the existing simulation codes, SPIS is designed to be used for a broad range of industrial and scientific applications. The simulation kernel is integrated into a complete modular pre-processing / computation / postprocessing framework, called SPIS/UI, allowing a high degree of integration of external tools, such as CAD, meshers and visualization libraries (VTK), and a very easy and flexible access to each level of the numerical modules via the Jython script language. Developed in an Open Source approach and oriented toward a community based development, SPIS is available for the whole community and is used by members of the European SPINE network. SPIS should address a large majority of the new challenges in spacecraft plasma interactions, including the environment of electric thruster systems, solar arrays plasma interactions, and modelling of scientific plasma instruments.

The numerical core and the user interface have been developed by ONERA and the Artenum company, respectively (Roussel et al., 2008 [9]). Various applications to spacecraft and ground experiment were performed by them and ESA (Roussel et al., 2010 [10], Hilgers et al. (2006) [11], Hilgers et al. (2008) [12], Roussel et al., 2008 [13]), Sarrailh et al., 2010 [14], Matéo-Vélez et al. (2008) [15], Matéo-Vélez et al., 2012 [16]).

The "SPIS-Science » extension, performed under ESA contract (N\# 4000102091/10/NL/AF) by ONERA and Artenum, aims at extending the capabilities of SPIS modelling framework for accurate evaluation of low-level surface electrostatic charging of science missions with low- energy plasma instruments. It also improves the code efficiency through multi-threading of PIC particle pusher (Matéo-Vélez et al., 2012 [17]). This evolution has been used in the present paper.

\section{Simulations set up}

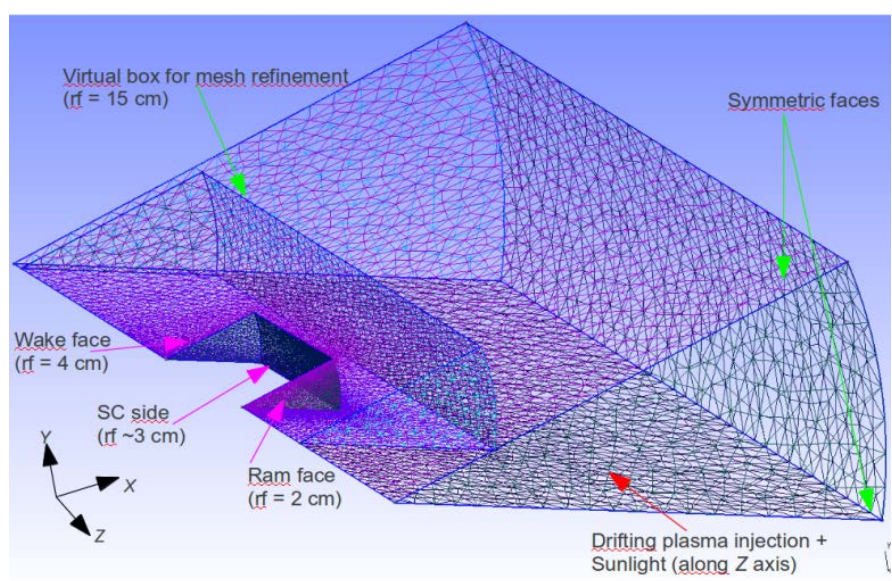

Figure 1: Geometry cut model of the cylinder (covered with ITO material) and the simulation box + the associated mesh ("rf" = mesh refinement)

The spacecraft geometry model used for all simulations is a cylinder ( $1 \mathrm{~m}$ radius and $2 \mathrm{~m}$ long) in a cylindrical simulation box. The whole system thus presents a symmetry of revolution around the $Z$ axis. SPIS handles the symmetries 
of fluxes and electric field. For a gain of CPU time, a cut geometry model is used with a $30^{\circ}$ angle around the $Z$ axis. The domain is a $5 \mathrm{~m}$ (in $X$ ) $\times 10 \mathrm{~m}$ (in $Z$ ) box, containing the satellite portion, with an unstructured meshing refined at $2 \mathrm{~cm}$ on the sunlit face of the satellite ( $4 \mathrm{~cm}$ on the rear side) and 50 $\mathrm{cm}$ on the edges of the simulation box (Figure 1). The external boundary conditions are set to a "Fourier" type (a $1 / r^{2}$ decrease of potential, $r$ being the distance to the spacecraft surface) where particles are injected and to a "mirror" type for the two symmetric faces (see Figure 1) which means that particles cannot cross those faces and are reflected into the simulation box.

The varying parameters between the simulations are: plasma properties (densities, temperatures, solar wind velocity), the sun flux (that varies as $1 / R^{2}, R$ being the distance to the Sun) and the time steps used in SPIS to compute every plasma population transport. To solve the equivalent electrical circuit representing the satellite the spacecraft capacitance is estimated at $C=1.910^{-10}$ Farad for a surface entirely covered with the conducting Indium Tin Oxide (ITO) material. The value of this parameter is however not important in this study since we are interested here in the steady state, rather than the transient phase.

All species (protons, thermal electrons, secondary electrons and photoelectrons) are computed using a Particle in Cell (PIC) model. In Table 1 the values in gray are directly entered in SPIS as input parameters. The secondary electron emission (SEE) is set with a characteristic energy of $2 \mathrm{eV}$ (Maxwellian velocity distribution function). The secondary emission yield (SEEY) curves (for true and backscattered electrons) are presented on Figure 2. The backscattered electrons are emitted with $2 / 3$ of their initial energy, however at those incoming energies the rates of backscattering are quite low ( $\sim$ for $T_{\text {the }}<50 \mathrm{eV}$ and $20 \%$ for $T_{\text {the }}=80 \mathrm{eV}$ ). Photoelectrons are emitted with a Maxwellian energy profile with temperature of $3 \mathrm{eV}$. Actually, measured interplanetary photoelectron spectra have sometimes higher energy components. A comparison test was provided by Guillemant et al. (2012) [7] and showed that photoelectrons with a
Maxwellian energy profile with temperature of $10 \mathrm{eV}$ (instead of $3 \mathrm{eV}$ ) lead (in a near Sun environment) to a more positive spacecraft potential ( +6 V of difference) as photoelectrons have more energy to spread further and escape the ram potential barrier. That is why in further work some more realistic distribution functions of photoelectrons should be considered. The satellite is considered static with respect to the solar wind so only the proton population speed (that depends on the distance to the Sun) is simulated. This velocity is considered to be only along the $-Z$ axis as we neglect the spacecraft orbital motion. This approximation has only a minor impact on the results as the ion Mach number would be of $\sim 4$ instead of $\sim 3.3$ and $I_{i}$ would slightly increase but stay the lowest current. The magnetic field is not taken into account, as proton and electron gyroradii are much greater than the simulation box, even at 0.044 AU (see Table 1).

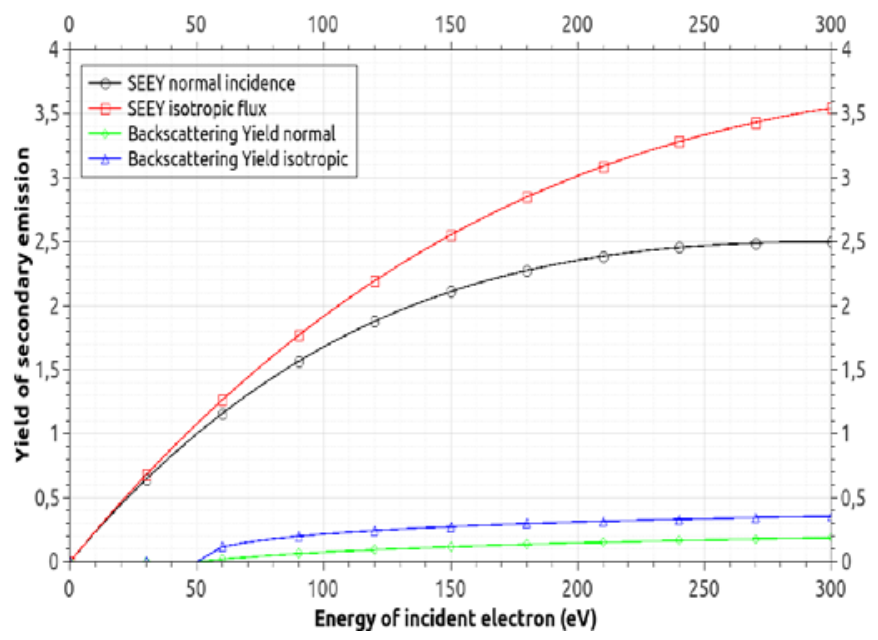

Figure 2: Secondary Electron Emission Yield (SEEY) and the backscattering yield for ITO material vs. incident electron energy (with a normal or isotropic incoming flux).

\begin{tabular}{|c|c|c|c|c|c|c|c|c|c|c|}
\hline PLASMA & Earth & Venus & Mercury Aph & rcury Peri & SO peri & SP+ 1st Peri & $0,11 \cup A$ & + Sci ops & 0,067 UA & SP+ Last Peri \\
\hline Distance (AU) & 1 & 0,72 & 0,46 & 0,3 & 0,25 & 0,162 & 0,11 & 0,093 & 0,067 & 0,044 \\
\hline Distance (Rs) & 215 & 154,8 & 98,9 & 64,5 & 53,75 & 34,83 & 23,65 & 19,995 & 14,405 & 9,46 \\
\hline Sun Flux (\#1AU) & 1,00 & 1,93 & 4,73 & 11,11 & 16,00 & 38,10 & 82,64 & 115,62 & 222,77 & 516,53 \\
\hline $\mathrm{Ne}=\mathrm{Ni}(\mathrm{m}-3)$ & $6,93 \mathrm{E}+06$ & $1,35 \mathrm{E}+07$ & $3,67 E+07$ & $8,85 E+07$ & $1,19 \mathrm{E}+08$ & $3,10 E+08$ & $8,03 E+08$ & $1,14 \mathrm{E}+09$ & $1,94 \mathrm{E}+09$ & $7,00 E+09$ \\
\hline $\mathrm{Te}(\mathrm{eV})$ & 8,14 & 10,41 & 14,52 & 19,80 & 22,95 & 31,77 & 41,50 & 48,33 & 59,25 & 84,47 \\
\hline $\mathrm{Ti}(\mathrm{eV})$ & 8,00 & 11,21 & 17,00 & 25,00 & 30,76 & 39,90 & 49,00 & 55,82 & 67,00 & 87,25 \\
\hline V ram protons (km/s) & 430,00 & 429,50 & 400,00 & 395,00 & 401,40 & 366,00 & 355,00 & 350,00 & 335,00 & 300,00 \\
\hline J_ph emitted on ITO (A/m2) & $3,21 \mathrm{E}-05$ & $6,19 \mathrm{E}-05$ & $1,52 \mathrm{E}-04$ & $3,57 \mathrm{E}-04$ & $5,14 \mathrm{E}-04$ & $1,22 \mathrm{E}-03$ & $2,65 \mathrm{E}-03$ & $3,71 \mathrm{E}-03$ & $7,15 \mathrm{E}-03$ & $1,66 \mathrm{E}-02$ \\
\hline J_the collected (A/m2) & $5,30 \mathrm{E}-07$ & $1,17 \mathrm{E}-06$ & $3,75 \mathrm{E}-06$ & $1,06 \mathrm{E}-05$ & $1,52 \mathrm{E}-05$ & $4,68 \mathrm{E}-05$ & $1,39 \mathrm{E}-04$ & $2,13 \mathrm{E}-04$ & $4,00 \mathrm{E}-04$ & $1,72 \mathrm{E}-03$ \\
\hline J_ion collected (A/m2) & $4,77 \mathrm{E}-07$ & $9,30 \mathrm{E}-07$ & $2,35 \mathrm{E}-06$ & $5,60 \mathrm{E}-06$ & $7,63 \mathrm{E}-06$ & $1,82 \mathrm{E}-05$ & $4,57 \mathrm{E}-05$ & $6,41 \mathrm{E}-05$ & $1,04 \mathrm{E}-04$ & $3,36 \mathrm{E}-04$ \\
\hline Mach number & 15,53 & 13,11 & 9,91 & 8,07 & 7,39 & 5,92 & 5,18 & 4,79 & 4,18 & 3,28 \\
\hline Debye length $(\mathrm{m})$ & 8,06 & 6,52 & 4,67 & 3,51 & 3,27 & 2,38 & 1,69 & 1,53 & 1,30 & 0,82 \\
\hline Debye length photoelec (m) & 0,98 & 0,71 & 0,45 & 0,29 & 0,25 & 0,16 & 0,11 & 0,09 & 0,07 & 0,04 \\
\hline SEEY (at Te) & 0,28 & 0,35 & 0,45 & 0,65 & 0,7 & 0,95 & 1,2 & 1,32 & 1,55 & 1,92 \\
\hline Thermal elec. Gyroradius ( $m$ ) & $1,66 \mathrm{E}+03$ & $1,12 \mathrm{E}+03$ & $4,76 \mathrm{E}+02$ & $2,73 E+02$ & $2,41 E+02$ & $1,21 E+02$ & $5,50 E+01$ & $4,93 \mathrm{E}+01$ & $1,88 \mathrm{E}+01$ & $1,47 \mathrm{E}+01$ \\
\hline Proton Gyroradius (m) & $7,05 E+04$ & $4,98 \mathrm{E}+04$ & $2,21 E+04$ & $1,31 E+04$ & $1,20 \mathrm{E}+04$ & $5,82 \mathrm{E}+03$ & $2,56 \mathrm{E}+03$ & $2,27 \mathrm{E}+03$ & $8,58 \mathrm{E}+02$ & $6,42 \mathrm{E}+02$ \\
\hline Magnetic field (T) & 5,80E-09 & $9,72 \mathrm{E}-09$ & $2,70 \mathrm{E}-08$ & $5,50 \mathrm{E}-08$ & $6,70 \mathrm{E}-08$ & 1,57E-07 & $3,95 \mathrm{E}-07$ & 4,76E-07 & 1,38E-06 & $2,10 \mathrm{E}-06$ \\
\hline
\end{tabular}




\section{SIMULATION RESULTS}

\section{A. Solar Probe Plus at $0.044 \mathrm{AU}$}

In this section are presented and discussed the results of the $0.044 \mathrm{AU}$ case. All population and potential maps are presented in a $X$ - $Z$ plane. The solar wind direction is towards the bottom of each map (in the $-Z$ direction).

This simulation is very similar to the case called "S3" in Guillemant et al. (2012) [7], studying the spacecraft-plasma interactions for a cylindrical conducting satellite at the perihelion of Solar Probe Plus (the other "S1,2,4,5" cases use a higher photoelectron emission yield). Both cases have been run using the SPIS software, with practically the same input parameters and identical covering material on the spacecraft (see Table 2). The main difference is the geometry model: in S3 it is an entire cylindrical satellite placed in a cylindrical simulation box while in this paper the whole geometry model has been cut with a $30^{\circ}$ angle around the $Z$ axis (see section II.C). This cut allowed a considerable meshing refinement for the latest simulation of about a factor 4 on all the grid compared to S3 and the value of $30^{\circ}$ was in this case a good compromise to keep enough meshing elements in the corners of the simulation box (avoiding risks of statistical issues in PIC modeling in those regions). Table 2 presents the inputs/outputs for the two simulations. Minor differences (particle temperatures, Sun flux) reflect that the parametric study requires more precision on input data interpolation at several distances from the Sun. Results are however very much comparable. However the meshing refinement plays an essential role for the numerical precision in the areas where the space charge is large (the ram and the wake).

\begin{tabular}{|c|c|c|}
\hline Simulation name & S3 & Case at $0.044 \mathrm{AU}$ \\
\hline Source & Guillemant et al. 2012 & This paper \\
\hline \multicolumn{3}{|l|}{ INPUTS } \\
\hline Distance from the Sun (AU) & 0,04 & 0,044 \\
\hline Sun Flux (\#1AU) & 500,00 & 516,53 \\
\hline Photoelectron yield J_ph (mA/m2) & 16,00 & 16,60 \\
\hline $\mathrm{Ne}=\mathrm{Ni}(\mathrm{m}-3)$ & $7,00 E+09$ & $7,00 E+09$ \\
\hline $\mathrm{Te}(\mathrm{eV})$ & 85,00 & 84,47 \\
\hline $\mathrm{Ti}(\mathrm{eV})$ & 82,00 & 87,25 \\
\hline V ram protons (km/s) & 300,00 & 300,00 \\
\hline Debye length (m) & 0,82 & 0,82 \\
\hline Debye length photoelec (m) & 0,04 & 0,04 \\
\hline SEEY & 1,92 & 1,92 \\
\hline Geometry SC & $\begin{array}{l}\text { ITO cylindrical 1m radius } \\
\text { x } 2 \mathrm{~m} \text { long }\end{array}$ & $\begin{array}{l}\text { ITO cut cylinder 1m } \\
\text { radius x } 2 \mathrm{~m} \text { long }\end{array}$ \\
\hline Geometry Simulation box & $\begin{array}{c}\text { cylindrical } 6 \mathrm{~m} \text { radius } \mathrm{x} \\
12 \mathrm{~m} \text { long }\end{array}$ & $\begin{array}{c}\text { cut cylinder } 5 \mathrm{~m} \text { radius } \mathrm{x} \\
10 \mathrm{~m} \text { long }\end{array}$ \\
\hline \multicolumn{2}{|l|}{ OUTPUTS } & $2 \mathrm{~cm} \rightarrow 50 \mathrm{~cm}$ \\
\hline Recollection - photoelectrons (\%) & 88,00 & 86,99 \\
\hline Recollection - 2nd electrons (\%) & 74,00 & 75,24 \\
\hline Spacecraft potential (V) & $-16,30$ & $-16,20$ \\
\hline Ram min value $(\mathrm{V})$ & $-25,00$ & $-25,42$ \\
\hline Wake min value (V) & $-29,50$ & $-31,30$ \\
\hline Ram barrier $(\mathrm{V})$ & $-8,70$ & $-9,19$ \\
\hline
\end{tabular}

Table 2: Comparison of inputs and outputs for 2 similar simulations (at 0.044 AU, from Guillemant et al. (2012) [7] and this paper
For this latter case, the satellite potential converges to $16.2 \mathrm{~V}$. Figure 3 is a plot of the plasma potential map and the population densities (thermal electrons, ions, photoelectrons and secondary electrons) around the spacecraft. Looking at the potentials, the lowest in the ram is at $-25.4 \mathrm{~V}$. With respect to the satellite it corresponds to a potential barrier for photoelectrons and secondary electrons of $-9.2 \mathrm{~V}$. In the ion wake a minimum of $-31 \mathrm{~V}$ is reached, which corresponds to a potential barrier for all secondaries of about $-15 \mathrm{~V}$. On the side of the cylinder a $-3 \mathrm{~V}$ barrier also forces the recollection of a fraction of secondaries. Those barriers are generated through the high densities of photoelectrons and secondary electrons in the front, and the high densities of secondary electrons added to the lack of ions at the rear. Looking at the positions of those plasma potential minimum values, in the ram it is located at $0.23 \mathrm{~m}$ from the sunlit face, which corresponds to 5 times the Debye length of photoelectrons $\left(\lambda_{\text {ph }}=0.04 \mathrm{~m}\right)$. In the wake the minimum is at $0.84 \mathrm{~m}$ which corresponds to the thermal electron and secondary electrons Debye length $(0.8 \mathrm{~m})$, which are predominant at this location. The level of the potential barrier in the ram is consistent with the photoelectron temperature.

An important parameter is the ratio between the dimension $L$ of the wake and $\lambda_{D \text {, the }}$ : if $L \sim \lambda_{D \text {, the }}$ the potential may be scaled at a fraction of $\sim k_{B} T_{e} / e$ in the wake. Indeed in the wake the minimum potential which can be obtained (using both Poisson's equation and Gauss's flux theorem), depending on the wake geometry (perfectly spherical or perfectly cylindrical), is resp. $\Phi=(0.5$ or 0.25$)\left(L / \lambda_{D}\right)^{2}\left(-k_{B} \cdot T_{e} / e\right)$. With $L$ the radius of the wake $(\sim 0.8 \mathrm{~m})$ and $\lambda_{D}$ the Debye length $(\sim 0.8 \mathrm{~m})$, we have in this case $\Phi$ between $\sim-40 \mathrm{~V}$ and $-20 \mathrm{~V}$. This simulation gives a wake minimum at $-31 \mathrm{~V}$ which seems like an intermediate case between the "bubble wake" and the "cylinder wake".

The potential surrounding the satellite is between $-25 \mathrm{~V}$ and $-31 \mathrm{~V}$. Those barriers represent about $1 / 3$ of the thermal electron temperature of $\sim 85 \mathrm{eV}$ so it affects their densities close to the spacecraft structure, as only $30 \%$ of the initial thermal electron density $\left(n_{0}=7 . \times 10^{9} \mathrm{~m}^{-3}\right)$ populates the region close to $\mathrm{SP}+$ (see the thermal electron map). The ion wake is clearly visible and varies between no particles near the rear face of the cylinder (in the wake) to $n_{0}$ around. The ion vacuum is reduced by the thermal diffusion of these particles and by ion focusing through the negative $\Phi_{S C}$. Local disturbances of the ion density at the front are due to statistic noise in the full PIC approach (the figure is not averaged enough such as to reduce noise). However, that does not impact the results since the problem is ruled by photoelectron density in the sheath. The denser plasma populations are still photoelectrons, emitted from the sunlit face at densities of about $10^{11} \mathrm{~m}^{-3}$ and they are spreading around until the wake region. The photoelectron reduction is also visible on the rear side of the cylinder, highly negative potential present there prevents photoelectrons from penetrating this area. Secondary electrons are dense over all surfaces of the spacecraft. The potential barriers have a great influence by preventing secondary electrons from escaping the front and the back faces 


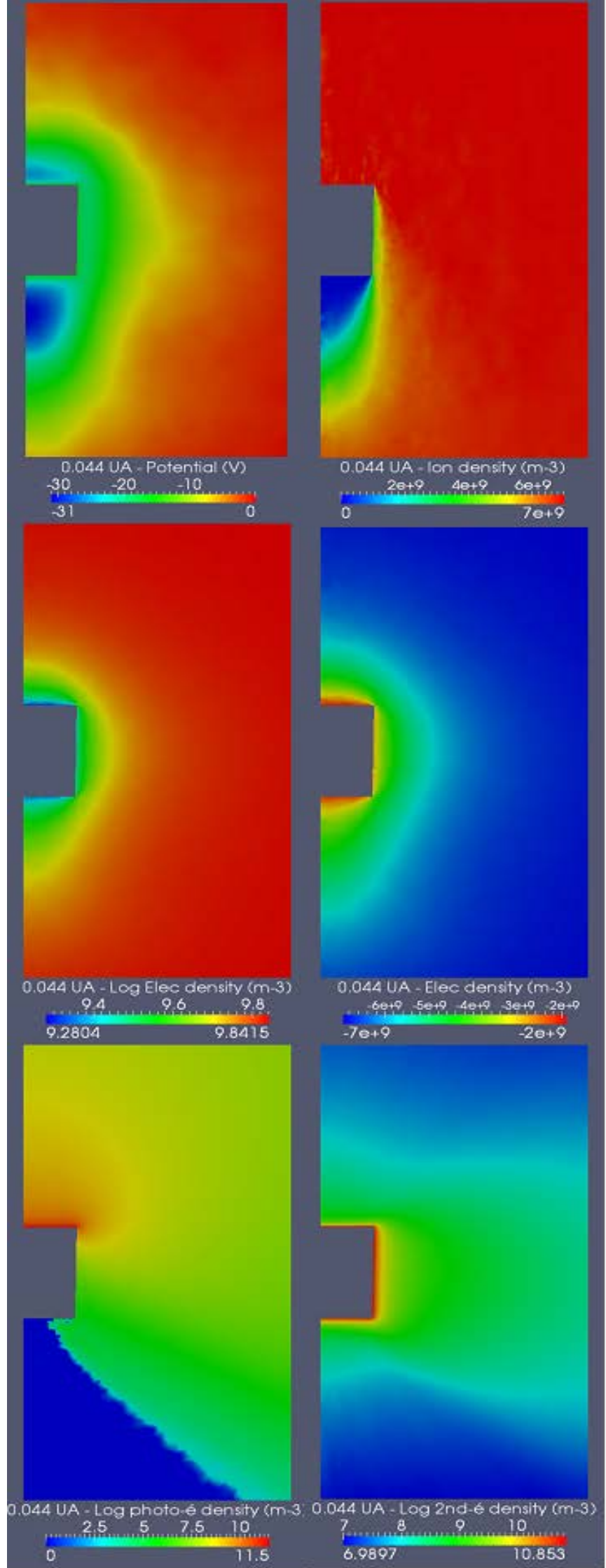

Figure 3: Simulation results for the $0.044 \mathrm{AU}$ case in a X-Z plane (Sun in the $+Z$ direction) of the spacecraft.

Table 3 shows all net currents on SP+ for all simulations. Concerning this first case, the total thermal electron current arriving on the spacecraft $I_{\text {the }}$ reaches $24.6 \mathrm{~mA}$ and for ions 1.5 $\mathrm{mA}$. Assuming thermal electrons treated as a fluid, like in the Maxwell-Boltzmann statistics equilibrium model approximation, theoretical net $I_{\text {the }}$ should reach $J_{\text {the }, 0} \times S_{S C} \times$ $\exp \left(e . \Phi_{S C} / k_{B} \cdot T_{e}\right)=26.8 \mathrm{~mA}$ (according to $J_{\text {the }, 0}$ in Table 1 and the spacecraft total surface of $S_{S C} \sim 18.9 \mathrm{~m}^{2}$ ). Of the 51.9 $\mathrm{mA}$ of photoelectron current emitted, $-45.2 \mathrm{~mA}$ is collected, for a net current of $6.7 \mathrm{~mA}$ ( $87 \%$ of recollection). For secondary electrons: $61.4 \mathrm{~mA}$ are emitted and $-46.2 \mathrm{~mA}$ collected, leading to a net current of secondaries of $15.2 \mathrm{~mA}$ ( $75 \%$ of recollection, all over the spacecraft surfaces). Plots of all currents are presented on Figure 7.

Those high rates of secondary and photoelectron recollection will definitely affect the low energy plasma measurements, especially the secondary particles whose recollection can occur all around the spacecraft. Those potential barriers also disturb the near environment of the spacecraft by filtering the thermal electrons and biasing the measurements. In this case, incoming thermal electrons with energies lower than $\sim 31 \mathrm{eV}$ will barely reach the satellite (for example those coming in the wake direction). Between the minimum potential position in the surrounding plasma and the spacecraft itself, electrons will be accelerated by an amount that depends on the height of the barrier (until $9 \mathrm{eV}$ in the ram and $15 \mathrm{eV}$ in the wake).

\section{B. Solar Orbiter at $0.25 \mathrm{UA}$}

We consider now a case in the region of Solar Orbiter closest perihelion at 0.25 UA to the Sun. Results for plasma potential and population densities are presented on Figure 4 . The final $\Phi_{S C}$ is now set at $+6.30 \mathrm{~V}$ This is due to the larger Debye length of photoelectrons: the barrier has changed from a $1 \mathrm{D}$ geometry at $0.044 \mathrm{AU}$ to a 3D geometry here. The recollection is thus less important and mainly due to the positive satellite potential. However, negative potential values are still present around the spacecraft: $-1.1 \mathrm{~V}$ at $1.6 \mathrm{~m}$ in front of the sunlit face in the ram (at $\sim 6$ times the photoelectron Debye length of $0.25 \mathrm{~m}$ ), and $-1 \mathrm{~V}$ at $2.9 \mathrm{~m}$ of the rear face in the wake (close to $\lambda_{\text {the }}$ which equals $3.27 \mathrm{~m}$ for ambient electrons). For secondary and photoelectrons, it represents respectively -7.4 and $-7.3 \mathrm{~V}$ barriers, added to the positively charged satellite which will thus attract them more efficiently. Incoming thermal electrons from environment encounter a -1 $\mathrm{V}$ barrier ( $\sim 4 \%$ of their mean kinetic energy of $23 \mathrm{eV}$ ) so they are not as much repelled as previously. However the distribution at the spacecraft surface is truncated at $\Phi_{S C}=$ +6.30 V: electrons have at least a $6.30 \mathrm{eV}$ energy on spacecraft.

Concerning the cylindrical ion wake obtained here, the minimum potential expected at its center (using the numerical application in section III.A with $L \sim 1 \mathrm{~m}$ and $\lambda_{D \text {, the }} \sim 3.27 \mathrm{~m}$ ) should be between $-1.2 \mathrm{~V}$ and $-0.6 \mathrm{~V}$. We effectively obtain -1 V. 


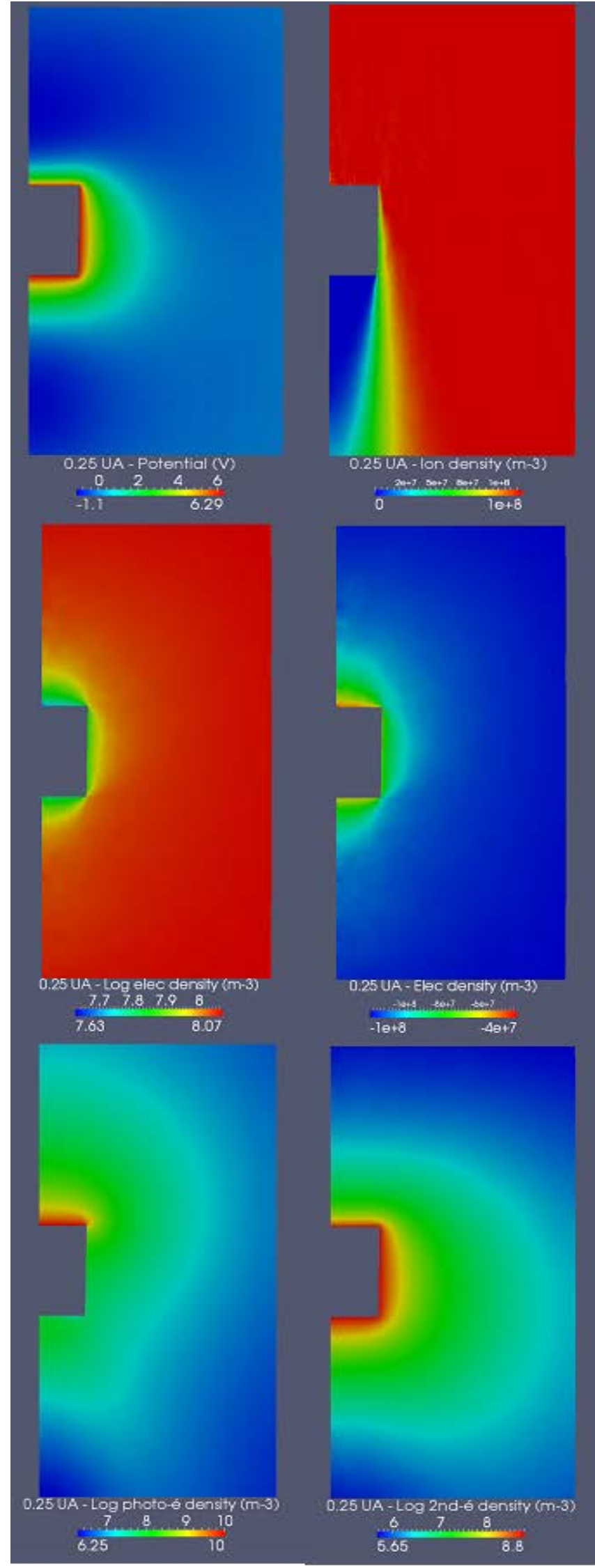

Figure 4: Simulation results for the $0.25 \mathrm{AU}$ case in a X-Z plane (Sun in the $+\mathrm{Z}$ direction)
Looking at plasma population densities, the major difference with the former simulation is the plasma potential structure around the cylinder. In the $0.25 \mathrm{AU}$ case it is more symmetric around the satellite body, less disturbed by the ion wake. This wake is more elongated along the $Z$ axis than before, as the ion speed is increased of $\sim 100 \mathrm{~km} / \mathrm{s}, T_{i}$ is divided by 4 , and there is no focusing of those particles as $\Phi_{S C}$ is now positive. As $\lambda_{\text {the }}=3.27 \mathrm{~m}$ (larger than the spacecraft dimension) the space charge in the wake only slightly modifies the potential (of about 1/10). The global behavior of photoelectrons and secondaries is identical to the first case, except that they are less dense than previously and they can spread farther from the cylinder because of the reduced potential barriers.

The recollection of secondary electrons reaches $80.8 \%$ and practically the same (78\%) for photoelectrons (Table 3). Here the recollection of secondaries, which is the condition for equilibrium, is achieved by a positive $\Phi_{S C}$, and a small barrier of potential due to space charge.

At 0.044 AU collected photoelectrons represented $\sim 40 \%$ of all collected currents on spacecraft, and the same proportion was reached for secondaries. At 0.25 AU the collected photoelectron current is now $60 \%$ of all collected currents while secondaries represent $\sim 20 \%$. This is due to the lower $\mathrm{SEY}$ at $23 \mathrm{eV}$ with respect to the SEY at $85 \mathrm{eV}$ : a lower emission leads to a lower recollection.

\section{Results between $1 \mathrm{AU}$ and $0.044 \mathrm{AU}$}

The same simulation was performed for several additional distances from the Sun, using the input parameters in Table 1. All the corresponding results (currents and potentials values) are displayed in Table 3. Plasma potential profiles along $Z$ and $X$ axis are displayed on Figure 5 and 6. Values of satellite potentials are plotted on Figure 7, location of minimum potentials is plotted on Figure 8.

Looking at the plasma potential profiles along the $Z$ axis, Figure 5 shows that for this type of model, below $\sim 0.3 \mathrm{AU}$ from the Sun, a non-monotonic evolution of potential is obtained, due to secondary electron and photoelectron space charge. Further, the space charge becomes less important. The transition between negative and positive satellite equilibrium potential is reached between 0.093 and $0.11 \mathrm{AU}$, but it has to be emphasized that this situation depends on the total spacecraft surfaces exposed to the environment and the type of covering materials.

The farther from the Sun, the farther the ram and wake minimum potential positions are located from the spacecraft surfaces. After $0.3 \mathrm{AU}$ the plasma potential profile is decreasing monotonically while looking farther from the cylinder. It is here visible for the cases at 0.46, 0.72 and $1 \mathrm{AU}$ to the Sun. Thus recollection of secondary particles in these regions is simply due to spacecraft positive potential. It can be noticed on Figure 7 that the simulation box almost reaches the limit of the sheath in each case. The plots of ram and wake minimum potentials should reach $0 \mathrm{~V}$ far enough from the body after $0.3 \mathrm{AU}$, but are slightly larger due to the simulation box boundaries that are still in the sheath. This restriction was necessary for reasons of CPU time consumption, and slightly affects the potential profiles in the surrounding plasma. 


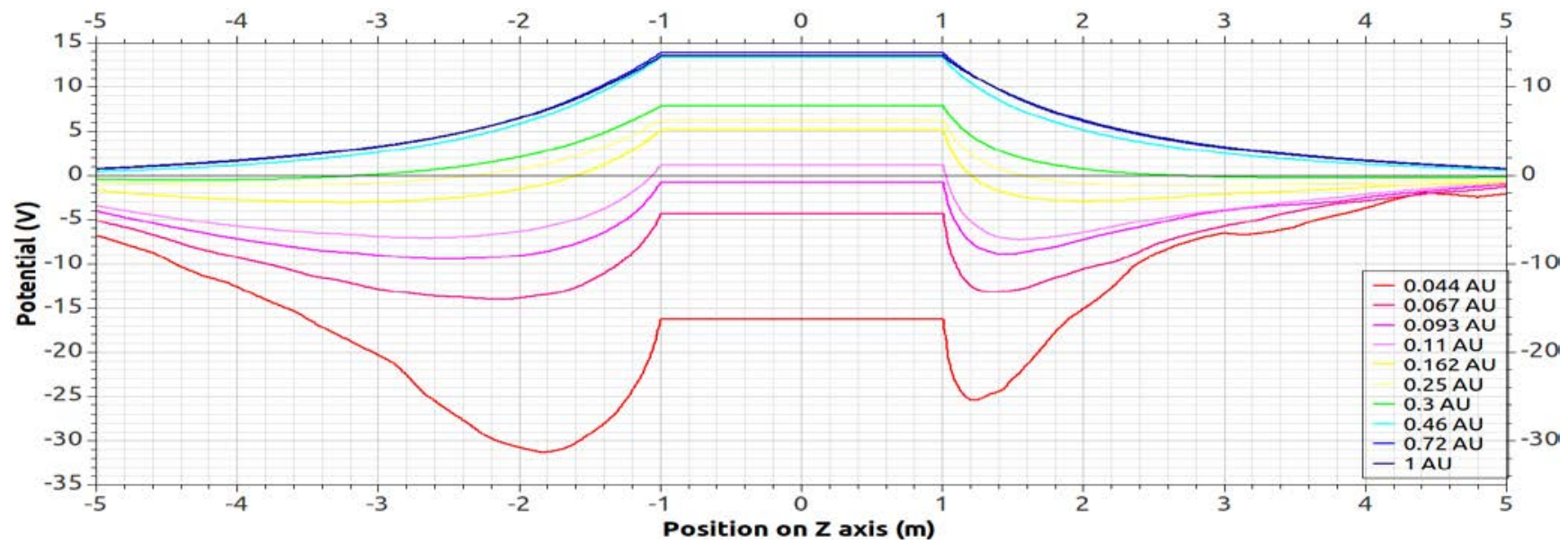

Figure 5: Plasma potential along $\mathrm{Z}$ axis for all simulations (the heliocentric distance is monotonically increasing with spacecraft potential)

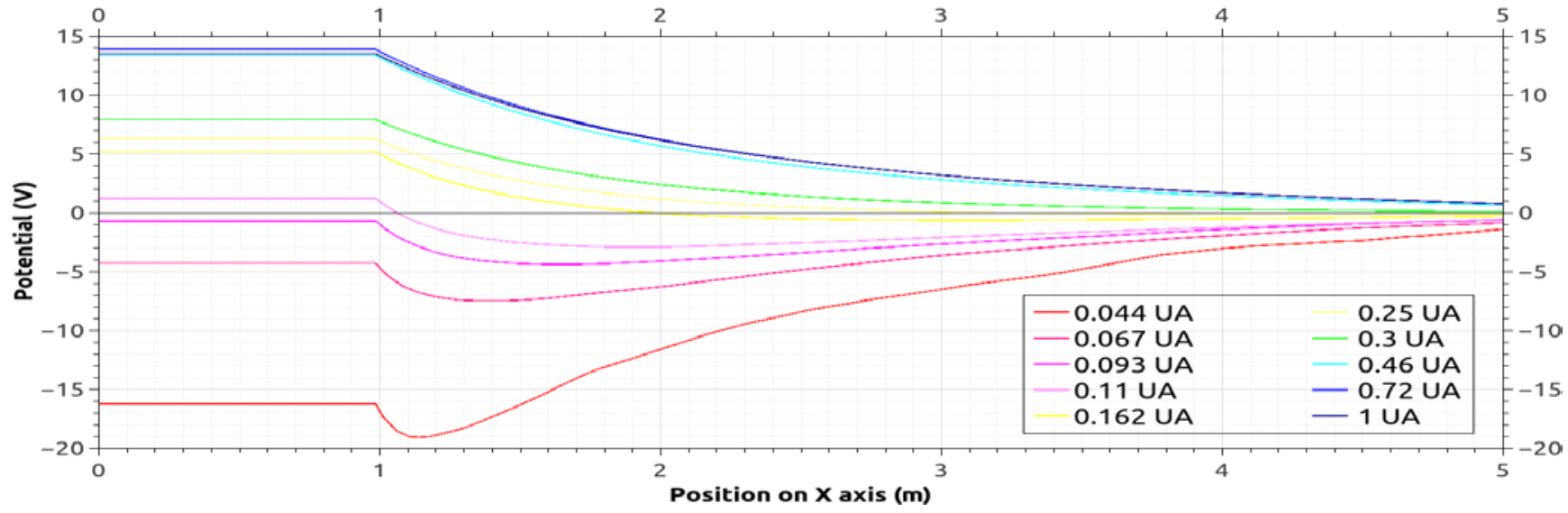

Figure 6: Plasma potential along $\mathrm{X}$ axis for all simulations (the heliocentric distance is monotonically increasing with spacecraft potential)

The transition between positively and negatively charged spacecraft is linked to the geometry of the sheath. It changes from a 3D sheath far from the Sun (farther than $0.11-0.093$ $\mathrm{AU}$, where thermal and photoelectrons Debye lengths are long) to a thin 1D sheath closer (with short Debye length of photoelectrons). In all cases the emitted-collected current equilibrium is reached once a significant part of photoelectrons is recollected, as it is the most important current. Far from the Sun, with no blocking from a potential barrier, the current balance is reached for a positive spacecraft potential (it is easier for photoelectrons to escape a 3D sheath). In the second case, the limitation from charge space is a $1 \mathrm{D}$ phenomena: the photoelectron recollection is extremely efficient (the net current being approximately given by the Child-Langmuir's law) and we can obtain the current balance with a negative spacecraft potential.

On Figure 8, we notice a difference in positioning of the minimum plasma potentials: below $\sim 0.3$ AU the wake potential barrier is farther from the spacecraft than the ram barrier. After $0.3 \mathrm{AU}$ the positions of the barriers regarding the facing surfaces are similar in the ram and in the wake. This also corresponds to regions where the potential along $Z$ axis evolves non monotonically. More precisely the Figure 8 suggests that below $0.093 \mathrm{AU}$ the ram barrier position regarding the sunlit face follows the photoelectron Debye length (which is much smaller than $\lambda_{\text {the }}$ ). Indeed when closer than $0.093 \mathrm{AU}$ the extreme near Sun UV flux generates high densities of photoelectrons that seem to influence most the plasma behavior in the ram. Until $0.25 \mathrm{AU}$ the ram barrier position is at about $5-6$ times $\lambda_{p h}$ to the sunlit face. After that, as it appears on Figure 8, the ram barrier distance to spacecraft is similar to the wake barrier distance and is comparable to the thermal Debye length. Within 0.25-0.3 AU the emitted secondary electron current becomes lower than the collected thermal current. On Figure 8 photoelectron and thermal electron Debye lengths as a function of heliocentric distance appear to be the two asymptotes between which are contained the ram and wake barriers position curves. As in the wake the plasma seems to be more influenced by thermal and secondary electrons (which are there present in quite similar densities), the potential barrier is controlled by the thermal electron Debye length and temperature, the spacecraft size and the ion Mach number.

Figure 9 makes explicit the part of secondary particles (both photoelectrons and SEE) among collected electrons on the spacecraft. In each case, between 0.044 and $1 \mathrm{AU}$, those non environmental particles represent $\sim 80 \%$ of the collection. Photoelectrons are more and more important in the recollection while looking farther from the Sun. This seems paradoxical but can be understood as the SEE is highly 


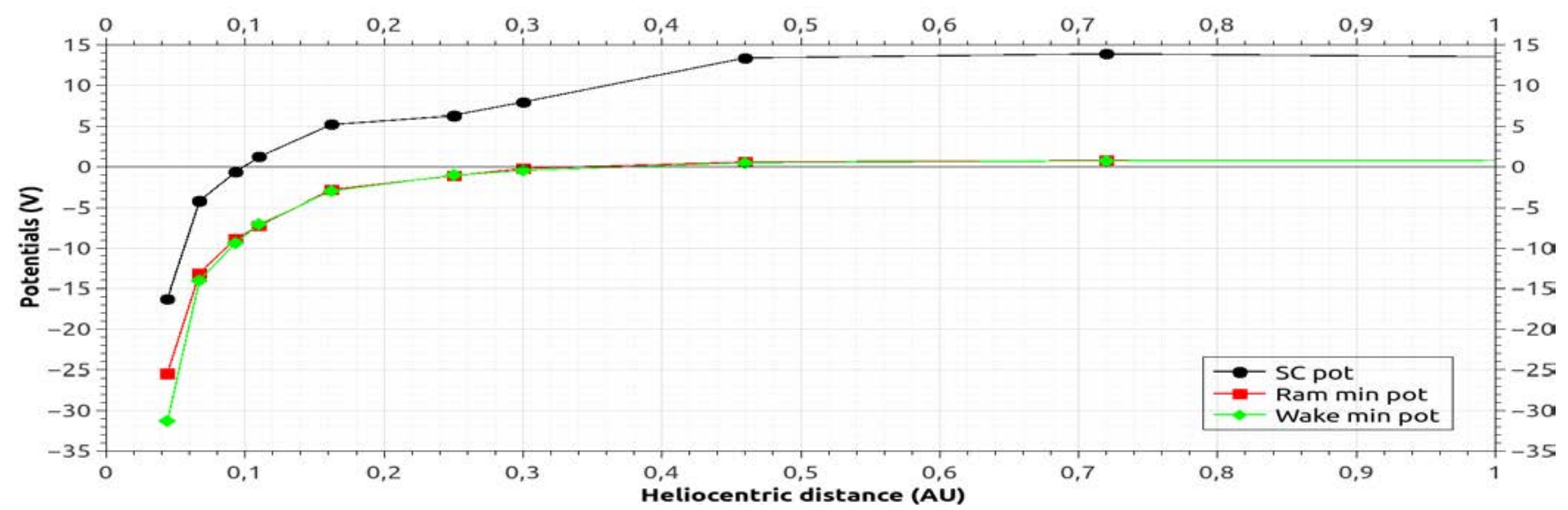

Figure 7: Potentials versus heliocentric distance.

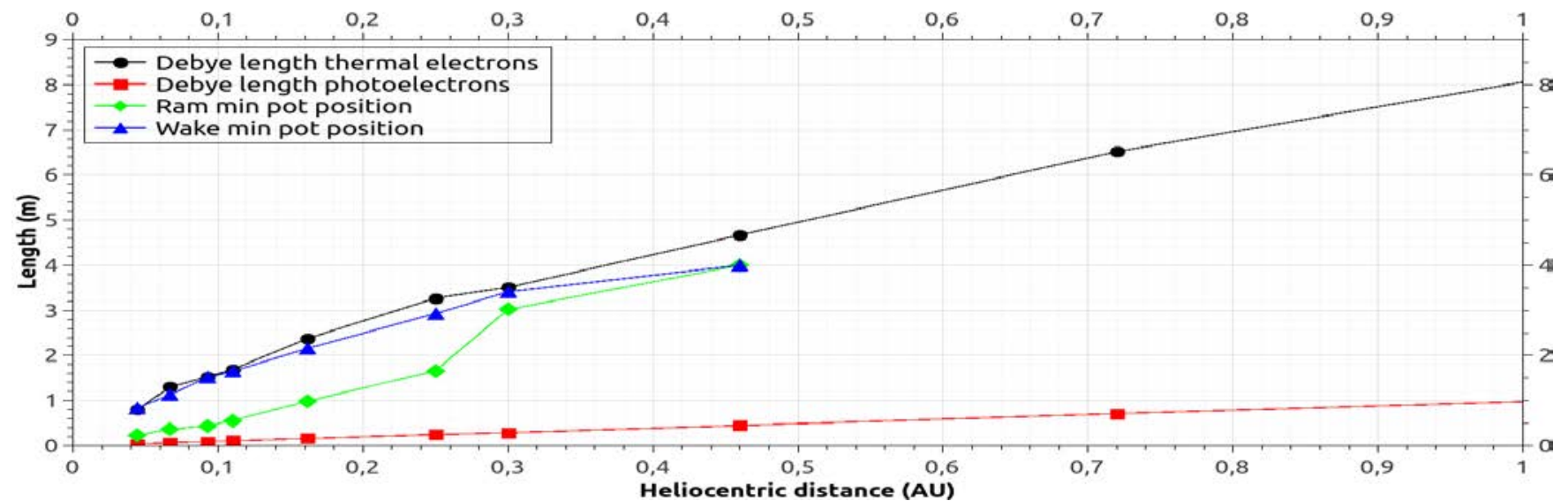

Figure 8: Comparison of Debye lengths \& locations of minimum potentials in plasma versus heliocentric distance

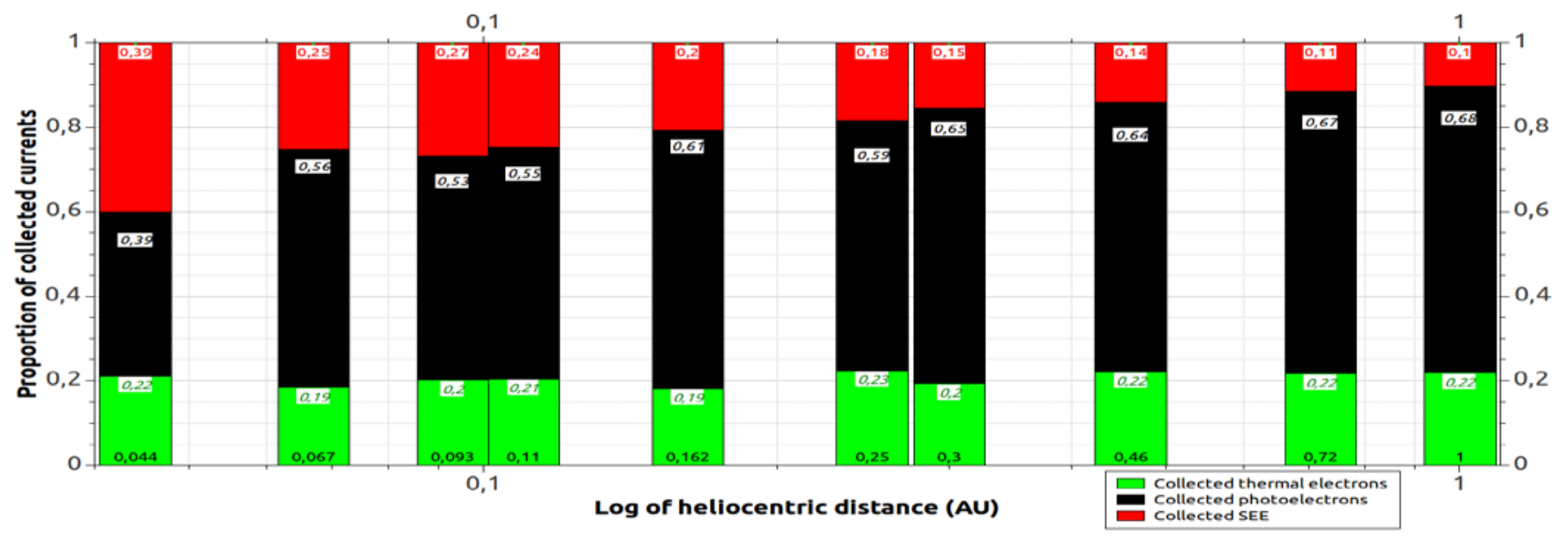

Figure 9: Proportion of particles among collected electrons versus heliocentric distance

reduced with increasing distance to Sun (because of the decreasing mean energy of the thermal electrons reducing consequently the secondary emission rate, see Figure 2). Fortunately, photoelectron recollection occurs essentially on the sunlit face and they will affect the detector entrance areas less than secondary electrons will.

\section{CONCLUSION}

The simulations performed in this work showed the variation of space charge potential barriers around a spacecraft depending on its distance to the Sun. At less than 0.3 AU for 


\begin{tabular}{|c|c|c|c|c|c|c|c|c|c|c|}
\hline \multirow{2}{*}{$\begin{array}{l}\text { PLASMA } \\
\text { CASE (AU) }\end{array}$} & \multirow{2}{*}{$\begin{array}{r}\text { Earth } \\
1 \\
\end{array}$} & \multicolumn{3}{|c|}{ Venus Mercury Aph Mercury Peri } & \multirow{2}{*}{\multicolumn{2}{|c|}{$\begin{array}{rr}\text { SO peri } & \text { SP+ 1st Peri } \\
0,25 & 0.162\end{array}$}} & \multirow{2}{*}{$\begin{array}{r}\mathbf{0 , 1 1} \text { UA } \\
0,11 \\
\end{array}$} & \multirow{2}{*}{$\begin{array}{r}\text { SP+ Sci ops } \\
0,093 \\
\end{array}$} & \multicolumn{2}{|c|}{ 0,067 UA SP+ Last Peri } \\
\hline & & 0,72 & 0,46 & 0,3 & & & & & 0,067 & 0,044 \\
\hline \multicolumn{11}{|l|}{ CURRENTS on SC (A) } \\
\hline Thermal electrons net & $-2,55 \mathrm{E}-05$ & $-4,98 \mathrm{E}-05$ & $-1,30 \mathrm{E}-04$ & $-2,68 \mathrm{E}-04$ & $-4,76 \mathrm{E}-04$ & $-9,39 E-04$ & $-2,63 E-03$ & $-3,78 \mathrm{E}-03$ & $-6,41 E-03$ & $-2,46 \mathrm{E}-02$ \\
\hline Ions net & $1,52 \mathrm{E}-06$ & $3,08 \mathrm{E}-06$ & $8,05 E-06$ & $2,07 \mathrm{E}-05$ & 2,93E-05 & 6,61E-05 & $1,73 E-04$ & 2,37E-04 & 4,00E-04 & $1,56 \mathrm{E}-03$ \\
\hline \multicolumn{11}{|l|}{ Photoelectrons } \\
\hline Collected & $-7,89 E-05$ & $-1,53 \mathrm{E}-04$ & $-3,73 E-04$ & $-9,00 \mathrm{E}-04$ & $-1,25 E-03$ & $-3,16 E-03$ & $-7,01 \mathrm{E}-03$ & $-9,89 \mathrm{E}-03$ & $-1,96 \mathrm{E}-02$ & $-4,52 \mathrm{E}-02$ \\
\hline Emitted & $1,01 \mathrm{E}-04$ & $1,94 \mathrm{E}-04$ & $4,75 \mathrm{E}-04$ & $1,12 \mathrm{E}-03$ & $1,61 \mathrm{E}-03$ & $3,83 \mathrm{E}-03$ & 8,31E-03 & $1,16 \mathrm{E}-02$ & $2,24 \mathrm{E}-02$ & $5,19 \mathrm{E}-02$ \\
\hline Net & 2,17E-05 & 4,05E-05 & 1,02E-04 & 2,17E-04 & 3,54E-04 & $6,75 \mathrm{E}-04$ & 1,30E-03 & 1,73E-03 & 2,77E-03 & $6,75 \mathrm{E}-03$ \\
\hline \multicolumn{11}{|l|}{ 2nd electrons } \\
\hline Collected & $-1,19 E-05$ & $-2,59 \mathrm{E}-05$ & $-8,18 \mathrm{E}-05$ & $-2,11 \mathrm{E}-04$ & $-3,89 \mathrm{E}-04$ & $-1,07 \mathrm{E}-03$ & $-3,16 E-03$ & $-5,01 E-03$ & $-8,71 E-03$ & $-4,62 E-02$ \\
\hline Emitted & 1,41E-05 & 3,18E-05 & 1,02E-04 & $2,40 \mathrm{E}-04$ & 4,82E-04 & 1,26E-03 & 4,24E-03 & $6,74 \mathrm{E}-03$ & 1,29E-02 & $6,14 \mathrm{E}-02$ \\
\hline Net & 2,27E-06 & 5,97E-06 & $1,99 \mathrm{E}-05$ & $2,86 \mathrm{E}-05$ & $9,26 \mathrm{E}-05$ & 1,87E-04 & $1,08 \mathrm{E}-03$ & $1,73 \mathrm{E}-03$ & $4,15 \mathrm{E}-03$ & $1,52 \mathrm{E}-02$ \\
\hline \multicolumn{11}{|l|}{ All populations } \\
\hline Collected & $-1,15 E-04$ & $-2,26 \mathrm{E}-04$ & $-5,77 \mathrm{E}-04$ & $-1,36 \mathrm{E}-03$ & $-2,09 \mathrm{E}-03$ & $-5,10 \mathrm{E}-03$ & $-1,26 \mathrm{E}-02$ & $-1,84 \mathrm{E}-02$ & $-3,43 E-02$ & $-1,14 \mathrm{E}-01$ \\
\hline Emitted & 1,15E-04 & $2,26 \mathrm{E}-04$ & 5,77E-04 & 1,36E-03 & 2,09E-03 & $5,08 \mathrm{E}-03$ & $1,25 E-02$ & 1,84E-02 & 3,53E-02 & 1,13E-01 \\
\hline Net & $-3,60$ E-09 & $-1,75 \mathrm{E}-07$ & $1,31 E-07$ & $-1,55 E-06$ & $-2,46 E-07$ & $-1,02 E-05$ & $-8,67 E-05$ & $-7,72 \mathrm{E}-05$ & $9,09 E-04$ & $-1,07 E-03$ \\
\hline \multicolumn{11}{|l|}{ Recollection (\%) } \\
\hline Photoelectrons & 78,44 & 79,11 & 78,54 & 80,59 & 77,99 & 82,38 & 84,39 & 85,08 & 87,61 & 86,99 \\
\hline 2nd electrons & 83,97 & 81,24 & 80,40 & 88,09 & 80,79 & 85,07 & 74,59 & 74,34 & 67,74 & 75,24 \\
\hline \multicolumn{11}{|l|}{ POTENTIALS } \\
\hline Spacecraft (V) & 13,53 & 13,89 & 13,39 & 7,91 & 6,29 & 5,21 & 1,22 & $-0,69$ & $-4,26$ & $-16,23$ \\
\hline Ram min position (m) & NA & NA & NA & 3,02 & 1,66 & 0,99 & 0,56 & 0,44 & 0,37 & 0,23 \\
\hline Wake min position (m) & NA & NA & NA & 3,41 & 2,93 & 2,16 & 1,65 & 1,52 & 1,13 & 0,84 \\
\hline Ram min value (V) & NA & NA & NA & $-0,23$ & $-1,13$ & $-2,84$ & $-7,23$ & $-8,88$ & $-13,13$ & $-25,42$ \\
\hline Wake min value $(\mathrm{V})$ & NA & NA & NA & $-0,47$ & $-1,07$ & -3 & $-7,06$ & $-9,39$ & $-14,01$ & $-31,3$ \\
\hline \multicolumn{11}{|c|}{ Potential barriers for secondaries (V) } \\
\hline Ram & 13,53 & 13,89 & 13,39 & $-8,14$ & $-7,42$ & $-8,05$ & $-8,45$ & $-8,19$ & $-8,87$ & $-9,19$ \\
\hline Wake & 13,53 & 13,89 & 13,39 & $-8,38$ & $-7,36$ & $-8,21$ & $-8,28$ & $-8,70$ & $-9,75$ & $-15,07$ \\
\hline \multicolumn{11}{|l|}{ OTHER VALUES } \\
\hline Rate 2nd-emission/the-coll & $-0,56$ & $-0,64$ & $-0,78$ & $-0,90$ & $-1,01$ & $-1,34$ & $-1,61$ & $-1,78$ & $-2,00$ & $-2,50$ \\
\hline Coll-The/Coll-ALL (\%) & 22,21 & 22,01 & 22,51 & 19,70 & 22,78 & 18,42 & 20,85 & 20,48 & 18,68 & 21,49 \\
\hline Coll-2nd/Coll-ALL (\%) & 10,35 & 11,44 & 14,17 & 15,55 & 18,62 & 20,95 & 25,02 & 27,17 & 25,36 & 40,40 \\
\hline Coll-photo/Coll-ALL (\%) & 68,77 & 67,91 & 64,71 & 66,27 & 60,00 & 61,92 & 55,50 & 53,63 & 57,13 & 39,48 \\
\hline
\end{tabular}

Table 3: Parametric study results, main outputs values

this geometry model, the plasma potential around the spacecraft decreases non monotonically. Potential barriers for secondary and photoelectrons thus appear and force their recollection to lower $\Phi_{S C}$ (even at negative values below 0.11 AU to the Sun). The barriers are created by high densities of secondary particles that control the surrounding plasma and are dominant in the collected particles.

The specific case studied at 0.25 AU showed that Solar Orbiter near its perihelion may be affected by those phenomena, even if they are less pronounced than at $0.044 \mathrm{AU}$ as the Solar Probe Plus perihelion. The measurement errors on low energy plasma measurements are possible but depend on the size of the spacecraft and its covering materials which will control secondary particles emission. At Solar Orbiter perihelion the low energy plasma measurements will be disturbed: high rates of secondary particles recollection can still occur and potential barriers still affect the surrounding plasma. A small fraction of incoming thermal electrons (with energies $\leq 1 \mathrm{eV}$ ) will be filtered and particles emitted from the satellite surfaces might be measured as noise by the onboard detectors, and thermal electrons arriving on the detectors will be accelerated (as $\Phi_{S C}>0$ ) at $6.3 \mathrm{eV}$.

Generally, the Solar Orbiter case requires further simulations, with a more precise geometry and physical model to anticipate the disturbances: more detailed geometry, exact material properties (solar panels materials, heat shield properties, taking into account thin wires and locations of plasma instruments...) and possibly electrical properties (equivalent resistors and capacitors inside the spacecraft and between the electrical nodes). The magnetic field has not been considered in this paper but might play a role in the plasma behavior (especially on the secondary particles trajectories) and the final $\Phi_{S C}$. This will be investigated in a forthcoming paper. We emphasize that the model used here has no link with the real Solar Orbiter geometry, but this simulation gives a first hint of the global plasma behavior in this region that SO will travel through. Actually, given the size of the real Solar Orbiter probe, sunshield and solar arrays, the created ion wake should be bigger and the corresponding potentials more negative, increasing the potential barriers and the biasing phenomena. However the electron instrument (SWA/EAS) is located at the end of a 4-5 $\mathrm{m}$ boom, behind the spacecraft, which might limit the influence of $\Phi_{S C}$. Moreover, the exposed covering materials (conductors and dielectrics) will generate different level of secondary particles. This subject will be studied in a forthcoming paper.

Concerning further developments, more relevant electron distribution functions of the solar wind need to be considered and their effects on spacecraft charging assessed. They might lead to much different results than obtained with Maxwellian distribution functions, and increase the disturbances of lowenergy particles measurements, as more high energy particles may generate higher SEY. This could be achieved by modelling the hot electron populations of the ambient plasma environment (the so called solar wind "Core, Halo and Strahl”). Indeed extrapolating data from Helios to Solar Orbiter (M. Maksimovic, private communication) and using associated modelling (Stverak et al., 2009) [19] it is possible to obtain the different electron population contributions. We will use this approach to set up SPIS with more detailed distribution functions for the ambient plasma. Concerning 
photoelectrons the use of a $3 \mathrm{eV}$ spectrum limits the positive charging and more realistic energy distribution functions should be investigated. Finally the implementation of virtual particle detectors within the simulations will give direct access to the plasma flux measured by instruments and enable a better assessment of biasing effects.

\section{ACKNOWLEDGMENT}

This work was supported in part by the International Space Science Institute (ISSI) in Bern, Switzerland. The authors wish to thank more particularly the team "Spacecraft interaction with space environment", led by Richard Marchand (University of Alberta, Canada), and its members for their interest and precious advices for our work (http://www.issibern.ch/teams/satspacenv/). The authors also wish to thank Benoît Lavraud (IRAP) and Milan Maksimovic (LESIA) for useful discussions.

\section{REFERENCES}

[1] Guernsey, R. L and Fu, J. H. M., J. Geophys. Res. 75, 3193, doi:10.1029/ JA075i016p03193 1970

[2] Whipple, E. C. Jr., Theory of spherically symmetric photoelectron sheath: a thick sheath approximation and comparison with the ATS 6 observation of a potential barrier, J. Geophys. Res., Volume 81, No 4, 1976.

[3] Zhao, H., Schmidt, R., Escoubet, C. P., Torkar, K. and Riedler, W., Selfconsistentdetermination of the electrostatic potential barrier due to the photoelectron sheath near a spacecraft, J. Geophys. Res., Volume 101, No. A7, Pages 15,653-15,659, 1996.

[4] Thiebault, B., Hilgers, A., Sasot, E., Laakso, H., Escoubet, C. P., Génot, V., and Forest, J., Potential barrier in the electrostatic sheath around a magnetospheric spacecraft, J. Geophys. Res., Volume 109, A12207, doi:10.1029/2004JA010398, 2004.

[5] Isensee, U., Plasma disturbances caused by the Helios spacecraft in the Solar Wind, J. Geophys., Volume 42, 581-589, 1977.

[6] Ergun, R. E., Malaspina, D. M., Bale, S. D., McFadden, J. P., Larson, D. E., Mozer, F. S., Meyer-Vernet, N., Maksimovic, M., Kellogg, P. J., and Wygant, J. R., Spacecraft charging and ion wake formation in the nearSun environment, Physics of Plasmas, Volume 17, Issue 7, pp. 072903072903-9, 1134 1150, 2010.

[7] Guillemant, S., Génot, V., Matéo-Vélez, J.-C., Ergun, R. E., Louarn, P., Solar Wind Plasma Interaction with Solar Probe Plus Spacecraft, submitted to Annales Geophysicae.

[8] Parker, E. N., "Dynamics of the interplanetary gas and magnetic fields," 128, 664, Astrophys. J., 1958

[9] Roussel J.-F., Rogier F., Dufour G., Mateo-Velez J.-C., Forest J., Hilgers A., Rodgers D., Girard L. and Payan D., SPIS Open Source Code: Methods, Capabilities, Achievements and Prospects, IEEE Trans. Plasma Sci., Vol 36, N 5, 2008.

[10] Roussel J.-F., Dufour G., Matéo-Vélez J.-C., Thiébault B., Andersson B., Rodgers D., Hilgers A., Payan D., SPIS multi time scale and multi physics capabilities: development and application to GEO charging and flashover modeling, to be published in IEEE Trans. on Plasma Physics.

[11] Hilgers, A., Thiébault, B., Estublier, D., Gengembre, E., Gonzalez, J., Tajmar, M., Roussel, J.-F., and Forest, J., A simple model of SMART-1 electrostatic potential variation, IEEE Trans. Plasma Sci, Vol 34, No5, pp 2159- 2165, DOI 10.1109/TPS.2006.883405, 2006.

[12] Hilgers, A., Clucas, S., Thiébault, B., Roussel, J.-F., Matéo-Vélez, J.-C., Forest, J., and Rodgers, D., Modelling of Plasma Probe Interactions With a PIC Code Using an Unstructured Mesh, IEEE Trans. Plasma Sci, Vol 36, No5 Part2, pp 2319-2323; DOI: 10.1109/TPS.2008.2003360, 2008.

[13] Roussel J.-F., Tondu T., Matéo-Vélez J.-C., Chesta E., D’Escrivan S., and Perraud L., Modeling of FEEP Electric Propulsion Plume Effects on Microscope Spacecraft, IEEE Trans. Plasma Sci., Vol 36, N 5, 2008.

[14] Sarrailh P., Matéo-Vélez J.-C., Roussel J.-F., Dirassen B., Forest J.,
Thiébault B., Rodgers D., Hilgers A., Comparison of numerical and experimental investigations on the ESD onset in the Inverted Potential Gradient situation in GEO, IEEE Trans. Plasma Sci., vol. 40, no. 2, pp. 368- 379, Feb. 2010.

[15] Matéo-Vélez J.-C., Roussel J.-F., Sarrail D., Boulay F., Inguimbert V. and Payan D., Ground Plasma Tank Modeling and Comparison to Measurements, IEEE Trans. Plasma Sci., Vol 36, N 5, 2008.

[16] Matéo-Vélez J.-C., Roussel J.-F., Inguimbert V., Cho M., Saito K., Payan D., SPIS and MUSCAT software comparison on LEO-like environment, IEEE Trans. Plasma Sci., vol. 40, no. 2, pp. 177- 182, Feb. 2012.

[17] Matéo-Vélez, J.-C., Sarrailh, P., Thiebault, B., Forest, J., Hilgers, A., Roussel, J.-F., Dufour, G., Rivière, B., Génot, V., Guillemant, S., Eriksson, A., Cully, C., Rodgers, D., SPIS Science: modelling spacecraft cleanliness for low-energy plasma measurement, in: Proceedings of 12th Spacecraft Charging Technology Conference, Kitakyushu, Japan, 14-18 May 2012.

[18] Engwall E., Eriksson A. I., and Forest J., (200 6), Wake formation behind positively charged spacecraft in flowing tenuous plasmas, Physics of Plasmas, 13, 062904, DOI: 10.1063/1.2199207

[19] Štverák Š., Maksimovic M., Trávnícek P. M., Marsch E., Fazakerley A. N., and Scime E. E. (2009), Radial evolution of nonthermal electron populations in the low-latitude solar wind: Helios, Cluster, and Ulysses Observations, J. of Geophys. Res., Vol. 114, Issue A5, CiteID A05104

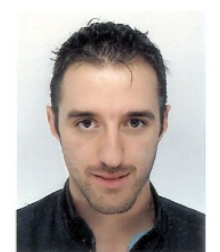

Stanislas Guillemant received his Master's degree in research in astrophysics and space sciences in 2007, the Master's degree in engineering in space technologies and instrumentation in 2008, both from the Université Paul Sabatier, Toulouse, France.

From 2009 to 2010 he was employed by Atos Origin as a study engineer and worked on several centers of space mechanics to control satellites orbits and attitude, and on the ground segment of the European positioning system Galileo. Since 2010 he is performing his $\mathrm{PhD}$ on spacecraft/plasma interactions in the Université Paul Sabatier, Toulouse, France, with the financial support of the Centre National des Etude Spatiales (CNES) and the Région Midi-Pyrénées. This $\mathrm{PhD}$ is performed in cosupervision between the Research Institute in Astrophysics and Planetology (IRAP) and the National Office of Aerospatial Studies and Research (ONERA).

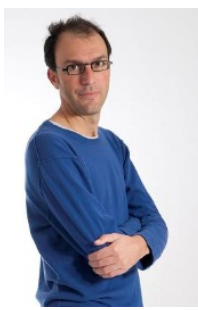

Vincent Génot received his Master's degree on spacecraft/plasma interactions from the Université of Versailles Saint-Quentin, France, in 1996 and the $\mathrm{PhD}$ on particle acceleration applied to terrestrial auroral regions from the Université of Versailles Saint-Quentin, France, in 1999. Both research dealt with plasma physics using numerical tools. During his post-doc in Queen Mary, University of London, UK, he worked on Cluster data analysis concerning mirror mode physics in the magnetosheath; he also proposed novel methods to correct moments of distribution function measured by particle detector from the effects of spacecraft potential.

From 2003 he joined the CESR (now the Research Institute in Astrophysics and Planetology IRAP) where he is continuing his research while teaching. In 2012 he became scientific director of CDPP, the French Plasma Physics Data Centre.

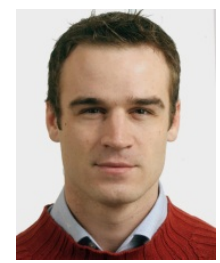

Jean-Charles Matéo-Vélez received the Master's degree in engineering in fluid mechanics from the Ecole Nationale Supérieure d'Electronique, d'Electrotechnique, d'Informatique, d'Hydraulique, et des Télécommunications, Toulouse, France, the Master's degree in research in fluid dynamics from Toulouse University, Toulouse, in 2003, and the PhD degree in fluid dynamics from SUPAERO (ISAE),

Toulouse, in 2006 .

Since 2007, he has been a Research Scientist with the Space Environment Department (DESP) of ONERA - the French Aerospace Lab. His research 
interests include spacecraft charging, ground tests of ESDs, and numerical modelling of spacecraft-plasma interaction.

Dr. Mateo-Velez has served as a referee for the IEEE Transactions on Plasma Science. He is a member of the Spacecraft Plasma Interaction Network in Europe (SPINE).

Pierre Sarrailh, photograph and biography not available at the time of publication.

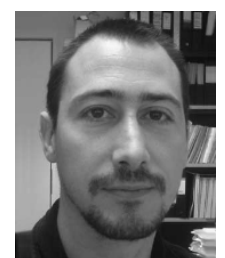

Alain Hilgers received the degree from Ecole Normale Supérieure, St Cloud, France and the $\mathrm{PhD}$ degree in Astrophysics from University Paris VII, Paris, France, in 1992.

Since 1993, he has been working at the European Space Agency [European Space Research and Technology Centre (ESTEC), NL, and European Space Agency Headquarters (ESA-HQ), F] in space environment modeling. His research and modelling activities mainly deal with space plasma instrumentation. He has also been temporary researcher at Centre d'Etude Terrestre et Planétaire (F), Swedish Institute of Space Physics (SE) and NOAA Space Environment Center (USA). He is also founder and chairman of the Spacecraft Plasma Interaction Network (SPINE).

Philippe Louarn, photograph and biography not available at the time of publication. 